\title{
Soluble Carbohydrates as Osmolytes in Several Halophytes from a Mediterranean Salt Marsh
}

\author{
Ricardo GIL ${ }^{1}$, Cristina LULL ${ }^{2}$, Monica BOSCAIU ${ }^{3}$, Inmaculada \\ BAUTISTA², Antonio LIDÓN²², Oscar VICENTE ${ }^{* *}$ \\ ${ }^{1}$ Universitat Politècnica de València, Instituto de Biología Molecular y Celular de Plantas (UPV-CSIC), CPI edificio \\ 8E, Camino de Vera s/n, 46022, Valencia, Spain; ovicente@ibmcp.upv.es ( ${ }^{*}$ corresponding author) \\ ${ }^{2}$ Universitat Politécnica de València, ReForest, Departamento de Ingeniería Hidráulica \\ y Medio Ambiente, Camino de Vera s/n, 46022, Valencia, Spain \\ ${ }^{3}$ Universitat Politècnica de València, Instituto Agroforestal Mediterráneo, CPI edificio 8E, Camino de Vera s/n, 46022, Valencia, Spain
}

\begin{abstract}
Compartmentalization of toxic ions in the vacuole and accumulation of osmolytes in the cytoplasm is a common response of halophytes to high soil salinity. Soluble carbohydrates, such as sugars and polyols, are some of the compatible solutes used for osmotic adjustment and osmoprotection. Major carbohydrates were identified and quantified by high-performance anion-exchange chromatography, combined with pulsed amperometric detection (HPAEC-PAD), in five halophytic species from a Mediterranean salt marsh (Juncus acutus, Juncus maritimus, Plantago crassifolia, Inula crithmoides and Sarcocornia fruticosa). Sucrose, followed by glucose and fructose were the more representative sugars detected in J. acutus and J. maritimus, and sorbitol the only soluble carbohydrate present at significant levels in $P$. crassifolia. In the other two taxa analyzed, no clearly predominant carbohydrates were observed: polyols $(m y o-$ inositol and glycerol) seemed to be the most representative in I. crithmoides, albeit at relatively low concentrations, and sugars (sucrose and glucose) in S. fruticosa. Multivariate statistical analysis was used to correlate soil properties and meteorological conditions increasing soil salinity, with seasonal changes in carbohydrate contents, to establish their possible function as osmolytes and their contribution to salt tolerance in the investigated species. The obtained results confirmed sorbitol as the major functional osmolyte in $P$. crassifolia-as it has been described previously for other species of the genus-and suggested the participation of sucrose and, to a lesser extent, glucose and fructose in osmoregulatory mechanisms in J. acutus and J. maritimus.
\end{abstract}

Keywords: abiotic stress, osmoprotectants, osmotic adjustment, polyols, salt stress, salt tolerance, soluble carbohydrates

\section{Introduction}

High soil salinity is one of the major environmental stress factors reducing the yield of crops in arable lands (Boyer, 1982; Owens, 2001), as well as affecting plant distribution in natural ecosystems (Bartels and Sunkar, 2005). The deleterious effects of salt on plants are well known (Flowers et al., 1986; Parida and Das, 2005; Serrano, 1996), and the responses of plants to salt stress have been the object of numerous studies, from botanical and ecological to physiological, biochemical and molecular perspectives (Boscaiu et al., 2005; Munns and Tester, 2008; Parvaiz and Satyawati, 2008; Sairam and Tyagi, 2004). However, little is known about the mechanisms of salt tolerance of plants in their natural habitats since, paradoxically, most studies have been carried out using salt-sensitive species (glycophytes), under artificial laboratory or greenhouse conditions. Salt-tolerant plants, or halophytes-defined as those able to survive and complete their life cycle at salt concentrations higher than 200 $\mathrm{mM} \mathrm{NaCl}$ (Flowers and Colmer, 2008)-seem to be, a priori, more convenient models to investigate salt tolerance mechanisms (for a more extensive discussion, see Grigore et al., 2011). Nevertheless, there are evidences that all plants, sensitive as well as tolerant, use similar, conserved mechanisms of response to high salinity-and to other environmental stress conditions causing cellular dehydration, such as drought, cold, high temperatures or heavy metalsinvolving, for example, the control of ion homeostasis and maintenance of cellular osmotic balance, the synthesis of 'protective' metabolites and proteins, and the activation of chemical and enzymatic antioxidant systems (Hussain et al., 2008; Vinocur and Altman, 2005; Zhu, 2001).

Salt tolerance of halophytes, in particular, seems to be largely dependent on their capacity to compartmentalize toxic ions in the vacuole and to accumulate compatible solutes in the cytoplasm (Flowers et al., 1986; Glenn et al., 1999). Apart from their role in osmotic adjustment, these 'compatible osmolytes' act as osmoprotectants, by directly stabilizing proteins and membrane structures under dehydration conditions, and by protecting the cell against oxidative stress as scavengers of ROS (Szabados and Savouré, 2010). Osmolytes are diverse from the chemical point of view, including some amino acids and derivatives (Gad- 
10

allah, 1999; Khan et al., 2000), sugars (Gao et al., 1998; Jouve et al., 2004), or sugar alcohols (polyols) (Ishitani et al., 1996; Koyro, 2006). Most studies found in the bibliography on the detection and quantification of osmolytes refer to nitrogenous compounds, such as proline (Pro) or glycine betaine (GB), which play an adaptive role in mediating osmotic adjustment and protecting subcellular structures in stressed plants (Ashraf and Harris, 2004). In fact, Pro and GB behave as almost omnipresent solutes, and it appears that species that are Pro accumulators show low levels of GB, and vice versa (Briens and Larher, 1982; Tipirdamaz et al., 2006). It has been suggested that the type of osmolyte used by different species could be used as a taxonomic criterion, but this point is far from clear, with the exception of some specific genera, due to the multiple evolutionary origins of salt tolerance in land plants (Flowers et al., 2010).

Not much is known about the role of carbohydrates as osmolytes in halophytes, but there are evidences that they also contribute to osmoregulation (e.g. Aubert et al., 1999; Gorham et al., 1980; Murakeözy et al., 2003), as they do in a large number of glycophytes. Soluble sugars are responsible for up to $50 \%$ of the total osmotic potential in glycophytes subjected to saline conditions (Cram, 1976). Relevant physiological studies have shown that soluble carbohydrates, such as glucose, fructose, sucrose, or fructans, significantly contribute to the mechanisms of adaptation to salt stress (Kerepesi and Galiba, 2000; Parida et al., 2002). Polyols also play an important role in the response to abiotic stress, compensating the reduced cell water potential (Popp and Smirnoff, 1995), and as oxygen radical scavengers (Ashraf and Harris, 2004); their hydroxyl groups could effectively replace water in establishing hydrogen bonds in the case of cellular dehydration, thus helping to maintain enzyme activities and to protect membrane structures (Noiraud et al., 2001). Thus-apart from their established functions as precursors of metabolic compounds, signalling molecules, and major cellular energy source (Gupta and Kaur, 2005; Hare et al., 1998)-in many plant species, including halophytes, carbohydrates probably share with other types of osmolytes their functions in maintenance of osmotic balance, osmoprotection and ROS scavenging, as well as molecules for carbon storage during stress (Parida and Das, 2005).

In reference to the detection and identification of soluble carbohydrates, numerous techniques have been developed over the years (BeMiller, 2010). High Perfomance Liquid Chromatography (HPLC), with its multiple variants, is the general method of choice for the separation of metabolites of many different chemical families (e.g. Gajewski et al., 2009; Koyuncu and Dilmaçünal, 2010). Highperformance anion-exchange chromatography combined with pulsed amperometric detection (HPAEC-PAD), in particular, has proven to be a highly sensitive and efficient separation tool for carbohydrate identification and analysis (Andersen and Sorensen, 2000; Cataldi et al., 2000).
The levels of different soluble carbohydrates with known osmolyte function have been determined in some representative halophytes from a Mediterranean salt marsh, several times during the length of the study, from summer 2009 to autumn 2010. The aims of this work were: 1) to identify and quantify the major sugars and/ or polyols present in each of the selected taxa, growing in their natural habitat, 2) to analyse seasonal changes in the levels of those putative osmolytes, and 3) to try and establish possible correlations between changes in the contents of specific carbohydrates and the degree of environmental stress, estimated by the parallel analysis of soil properties and climatic conditions in the experimental area. It was hypothesised that those sugars playing a role in the mechanisms of salt tolerance in a given species, that is, with a biological function as osmolytes, should accumulate at significantly higher levels in periods of strong stress than under milder environmental conditions.

\section{Materials and methods}

\section{Plant material}

Plant samples from different halophytes were collected in the Natural Park of 'Devesa de la Albufera', near the city of Valencia, SE Spain (39 $21^{\prime} \mathrm{N}$; $\left.0^{\circ} 19^{\prime} \mathrm{W}\right)$. The sampling zone is located in one of the so-called 'malladas', which are characteristic salt marshes in depressed areas separated from the sea by coastal dunes. An experimental plot was defined in a not flooded sandy area, based on the presence of taxa of interest. Two monocotyledonous halophytes belonging to the Juncaceae family (Juncus acutus L. and J. maritimus Lam.) and three succulent dicotyledonous species-Sarcocornia fruticosa (L.) A. J. Scott. (Chenopodiaceae), Inula crithmoides L. (Compositae), and Plantago crassifolia Forssk. (Plantaginaceae)-were selected for this study. Juncus culms, $P$. crassifolia leaves and succulent branches of $S$. fruticosa and I. crithmoides, were collected from five individuals of each species. Sampling was repeated periodically, in different seasons, from summer 2009 to autumn 2010 (the sampling dates were: 1-Jul-09, 30-Nov09, 19-May-10, 13-Jul-10, and 23-Nov-10). Each time, the samples were obtained from the same individuals, which were marked in the field but also georeferenced. Plant material was cooled on ice and transported to the laboratory, where part of it was frozen and stored at $-75^{\circ} \mathrm{C}$, and the rest dried in the oven at $65^{\circ} \mathrm{C}$ for $3-4$ days, until constant weight, to obtain the percentage of dry weight of each individual.

\section{Soil properties}

Three soil samples were collected from 0 to $15 \mathrm{~cm}$ depth simultaneously with the plant material, air-dried and passed through a $2 \mathrm{~mm}$ sieve to remove coarse fragments before laboratory analysis. Soil $\mathrm{pH}$ was measured in soil suspensions in a soil-to-water ratio of 1:2.5 (w/v) using a Crison MicropH 2001 pH-meter. Electrical conduc- 
tivity (EC) was measured in aqueous extracts at a soil-towater ratio of $1: 1(\mathrm{w} / \mathrm{v})$ in a Crison 522 conductivimeter. Soil oxidable organic carbon (SOC) was determined by the Walkley-Black dichromate oxidation method (Nelson and Sommers, 1982), and water holding capacity as water retained at $20 \mathrm{kPa}$ in a pressure chamber.

\section{Meteorological data}

Meteorological information on precipitation, temperature and evapotranspiration (ETP), registered in the nearest station located in Picassent (Valencia), were obtained from the Agroclimatic Information System for Irrigation (SIAR) of the Spanish Ministry of Environment, Rural and Marine Affairs (MARM).

\section{Extraction of soluble sugars}

Plant samples were ground in a mortar, in the presence of liquid nitrogen, until a fine powder was obtained. Up to $200 \mathrm{mg}$ of this material was suspended in $1 \mathrm{ml}$ milliQ water; the solution was supplemented with raffinose, as an internal standard, transferred to a $2 \mathrm{ml}$ centrifuge tube and vortexed, thereafter incubated at $95^{\circ} \mathrm{C}$ for $10 \mathrm{~min}$, sonicated $5 \mathrm{~min}$, and then centrifuged at $12000 \mathrm{rpm}$ for $10 \mathrm{~min}$ in a table-top Eppendorf centrifuge, to eliminate debris. One $\mathrm{ml}$ of the supernatant was filtered through a Sep-Pak plus $\mathrm{C} 18$ solid phase cartridge (Waters, Barcelona, Spain) and diluted to $4.5 \mathrm{ml}$ with milliQ water. An aliquot of 20 $\mu \mathrm{l}$ of each extract was analysed by high performance liquid chromatography.

\section{Carbohydrate analysis}

Six major sugars or polyols were determined in the plant extracts, namely myo-inositol, glycerol, sorbitol, glucose, fructose, and sucrose (by elution order). Highperformance anion-exchange chromatography (HPAEC) combined with pulsed amperometric detection (PAD), was used for carbohydrate separation and detection. Analyses were performed using a non-metallic isocratic pump, model 515 (Waters), a pulsed amperometric detector, model 464 (Waters), and a manual injection valve with a 20- $\mu$ l injection loop. A Hamilton (Bonaduz, Switzerland) RCX-10 anion-exchange column ( $250 \mathrm{~mm}$ long $\mathrm{x} 4.1 \mathrm{~mm}$ i.d., $7 \mu \mathrm{m}$ particle size), was used for carbohydrate separation. The analytical column was regenerated at the beginning of each working day by flushing with $50 \mathrm{~mL}$ of $0.1 \mathrm{~N}$ carbonate-free $\mathrm{NaOH}$. Chromatography data acquisition and processing was performed using the Empower 2 pro. software for Windows (Waters). Pulsed amperometric detection was carried out with the following pulse potentials $\left(\mathrm{E}_{1}\right.$, measurement potential; $\mathrm{E}_{2}$, cleaning potential; $\mathrm{E}_{3}$, conditioning potential) and times: $\mathrm{E}_{1}=-80 \mathrm{mV}\left(\mathrm{t}_{1}=\right.$ $260 \mathrm{~ms}), \mathrm{E}_{2}=-570 \mathrm{mV}\left(\mathrm{t}_{2}=260 \mathrm{~ms}\right), \mathrm{E}_{3}=-730 \mathrm{mV}\left(\mathrm{t}_{3}=\right.$ $360 \mathrm{~ms}$ ). The detection potential was chosen so that carbohydrates could be detected with the lowest background current. All experiments were carried out at $21^{\circ} \mathrm{C}$ under isocratic conditions with $100 \mathrm{mM} \mathrm{NaOH}$ (flow-rate: 1.0

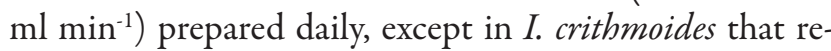

quired $30 \mathrm{mM} \mathrm{NaOH}$ (at the same flow rate) for separating chromatographic peaks; the mobile phase was sparged with helium gas at the beginning of each analytical run. Stock solutions of the standards were prepared in milliQ water and stored at $-20^{\circ} \mathrm{C}$ until used. The quantitative determination was done according to calibration lines ranging from 0.01 to $4.5 \mathrm{mM}$ of the standards. The correlation coefficients obtained $\left(\mathrm{r}^{2}\right)$ were higher than 0.999 .

\section{Statistical analysis}

A comparison was made with respect to the major carbohydrates detected in the investigated halophytes and the sampling seasons. The computer program STATGRAPHICS Centurion v.16 (Statistical Graphics Corp.) was used for the statistical analysis. Analysis of variance (one-way ANOVA) followed by Least Significant Difference test (LSD) was used to separate the means of samplings, with a minimum confidence interval of $95 \%$. Prior to ANOVA, sugar concentration data were normalized by logarithmic transformation (LOG). The multivariate statistical technique of Principal Components Analysis (PCA) was used to correlate the carbohydrate levels with the environmental variables studied. The new principal components or factors were linear combinations of the original variables, and independent of each other. Pearson product-moment correlation coefficient $(r)$ was applied to determine the significance level of correlations.

\section{Results and discussion}

\section{Soil analysis and climate data}

Some soil properties of the experimental zone are presented in Tab. 1; they did not vary significantly in different seasons, and are similar to those of other salt marshes previously analysed in the Natural Park of 'Devesa de La Albufera' (Lidón et al., 2009). The sandy texture of the soil in this area ( 96.2 sand: 0.6 silt: 3.2 clay, in percentage) makes difficult the retention of water, but the most important factor conditioning plant survival is the high salinity. In fact, the groundwater level, the flooding regime and the salinity are widely considered as the most important factors affecting plant distribution in saline environments (Chapman, 1974). Soil moisture and salinity normally vary during the year, in alternating dry periods, in which salts are accumulated in the upper soil horizon, and wet periods,

Tab. 1. Soil properties of the sampling zone at $0-15 \mathrm{~cm}$ depth. Values shown are the means (with standard deviations) of the different parameters, from samples collected in summer 2009, autumn 2009 and spring 2010, three replicates per sampling (n $=9)$

\begin{tabular}{cc}
\hline Soil properties & Mean \pm SD \\
\hline $\mathrm{pH}$ & $8.91 \pm 0.31$ \\
$\mathrm{WHC} 20 \mathrm{kPa}^{\mathrm{a}}(\%)$ & $3.84 \pm 0.95$ \\
$\mathrm{SOC}^{\mathrm{b}}\left(\mathrm{g} \mathrm{kg}^{-1}\right)$ & $9.3 \pm 2.75$ \\
\hline
\end{tabular}

aHC: water-holding capacity (water content by weight); ${ }^{\text {SSOC: }}$ soil oxidable organic carbon 
12

in which salts are diluted (Álvarez-Rogel et al., 2007). The rise of salts to the surface by evaporation and their washing by rain induces a cyclic variation of soil salinity in function of environmental conditions. Seasonal variation of salinity (measured as electrical conductivity of the soil) and other climatic variables are shown in Tab. 2. As expected, soil salinity and temperatures were significantly higher in summer 2009 and 2010, as compared to the other seasons; in those periods, elevated temperatures and low rainfall resulted in higher evapotranspiration and water deficit. However, the two years of the study were quite different meteorologically. The first year was generally drier, and the summer sampling was preceded by a strong drought: the accumulated rainfall during the two months before collection of plant material amounted to only $8.61 \mathrm{~m}^{-2}$, as compared to $551 \mathrm{~m}^{-2}$ in the same period of 2010 , which was very rainy during winter and spring, resulting in higher soil humidity (data not shown). Therefore, including all samplings, summer 2009 was the period when plants had been subjected to a higher degree of environmental stress.

Average carbohydrate contents in the selected halophytes

To establish the predominant sugar(s) present in the halophytic species under study, six major soluble carbohydrates, namely myo-inositol, glycerol, sorbitol, glucose, fructose, and sucrose, were determined in extracts of plants collected in five successive samplings, from summer 2009 to autumn 2010; the average values of all samples are shown in Tab. 3, for the five investigated taxa. From these data, it is clear that the patterns of carbohydrate accumulation differ widely in the different species analysed, except for the closely related Juncus acutus and J. maritimus; both taxa accumulated relatively high levels of sucrose and, to a lesser extent, glucose and fructose, but showed very low polyol contents.

Sorbitol was the major carbohydrate detected in Plantago crassifolia, which contained very low levels of the rest of sugars and polyols. This result support the notion that sorbitol is the osmolyte used specifically by plants of this genus-and probably in the whole Plantaginaceae family (Flowers et al., 2010). Sorbitol has been described as the most abundant soluble carbohydrate in all Plantago species analysed, including taxa with different degrees of salt tolerance, from typical halophytes such as $P$. maritima to glycophytes such as P. major (Ahmad et al., 1979; Königshofer, 1983; Koyro, 2006; Pommerrenig et al., 2007).

Inula crithmoides contained very low levels of all sugars, and between 2 and 4-fold higher levels of polyols (except sorbitol), whereas Sarcocornia fruticosa accumulated predominantly glucose and sucrose but showed low polyol contents (Tab. 3). It should be mentioned that no additional major peaks were observed in the chromatograms, excluding the possibility that other unidentified sugars or polyols could play a significant role as osmolytes in the investigated species.

\section{Seasonal changes in carbohydrate contents}

Seasonal changes in carbohydrate contents in the plants were analysed, to establish possible correlations with changes in their environmental conditions. The results obtained are shown in Fig. 1 for the two Juncus species and in Fig. 2 for the three succulent halophytes, P. crassifolia, I. crithmoides and $S$. fruticosa. Those sugars and polyols pres-

Tab. 2. Seasonal changes in soil and climatic variables in the sampling zone. EC: electrical conductivity (1:1 w/v); P: precipitation; ETP: evapotranspiration; WD: water deficit; Av. T: average temperature; Max. T: maximum temperature; Min. T: minimum temperature. EC values shown are the means (with standard deviations) of three random samples collected in the experimental zone $(n=3)$. Temperature values correspond to the means $( \pm S D)$ of weekly data during the month previous to the sampling day, in each season $(n=4)$. 'Accumulated' values are the sum of weekly data during the month previous to the sampling day, in each season $(n=4)$

\begin{tabular}{cccccccc}
\hline \multirow{2}{*}{ Season } & \multicolumn{3}{c}{ Mean $\pm \mathrm{SD}^{1}$} & \multicolumn{3}{c}{ Accumulated } \\
\cline { 2 - 7 } & $\left.\mathrm{EC}(\mathrm{dS} \mathrm{m})^{-1}\right)$ & Av. T $\left({ }^{\circ} \mathrm{C}\right)$ & $\operatorname{Max}^{\mathrm{T}}\left({ }^{\circ} \mathrm{C}\right)$ & Min. T $\left({ }^{\circ} \mathrm{C}\right)$ & $\mathrm{P}(\mathrm{mm})$ & $\mathrm{ETP}(\mathrm{mm})$ & WD $(\mathrm{mm})$ \\
\hline Summer 2009 & $2.81 \pm 0.61^{\mathrm{a}}$ & $23.92 \pm 0.93^{\mathrm{a}}$ & $33.01 \pm 0.90^{\mathrm{a}}$ & $15.99 \pm 1.78^{\mathrm{a}}$ & 0 & 157.36 & 157.36 \\
Autumn 2009 & $0.52 \pm 0.16^{\mathrm{bc}}$ & $18.39 \pm 1.64^{\mathrm{b}}$ & $27.82 \pm 1.65^{\mathrm{b}}$ & $11.19 \pm 2.03^{\mathrm{b}}$ & 30.60 & 60.84 & 30.24 \\
Spring 2010 & $0.21 \pm 0.03^{\mathrm{c}}$ & $13.49 \pm 2.01^{\mathrm{c}}$ & $22.05 \pm 2.69^{\mathrm{c}}$ & $6.48 \pm 2.31^{\mathrm{c}}$ & 49.80 & 80.68 & 30.88 \\
Summer 2010 & $2.66 \pm 0.55^{\mathrm{a}}$ & $24.21 \pm 2.20^{\mathrm{a}}$ & $32.34 \pm 1.74^{\mathrm{a}}$ & $15.48 \pm 3.46^{\mathrm{a}}$ & 0.20 & 151.28 & 151.08 \\
Autumn 2010 & $1.33 \pm 0.28^{\mathrm{b}}$ & $13.21 \pm 2.64^{\mathrm{c}}$ & $21.34 \pm 3.06^{\mathrm{c}}$ & $5.48 \pm 2.90^{\mathrm{c}}$ & 11.60 & 57.16 & 45.56 \\
\hline
\end{tabular}

${ }^{1}$ Numbers followed by the same letter within a column are not significantly different $(\mathrm{P}>0.05$; ANOVA followed by LSD)

Tab. 3. Average contents of major soluble carbohydrates in the selected halophytic species. Values correspond to the means (with standard deviations) of samples collected in different seasons $(n=5)$, from summer 2009 to autumn 2010

\begin{tabular}{ccccccc}
\hline \multirow{2}{*}{ Plant species } & \multicolumn{5}{c}{ Carbohydrate contents $\left(\mu \mathrm{mol} \mathrm{g}^{-1} \mathrm{DW}\right)$} \\
\cline { 2 - 7 } & myo-Inositol & Glicerol & Sorbitol & Glucose & Fructose & Sucrose \\
\hline J. acutus & $2.92 \pm 0.58$ & $0.56 \pm 0.17$ & $0.17 \pm 0.04$ & $39.14 \pm 8.86$ & $39.1 \pm 7.45$ & $100.06 \pm 24.87$ \\
J. maritimus & $2.32 \pm 0.34$ & $1.16 \pm 0.47$ & $0.34 \pm 0.09$ & $30.83 \pm 6.18$ & $29.46 \pm 4.52$ & $91.42 \pm 17.65$ \\
P. crassifolia & $6.1 \pm 1.62$ & $0.62 \pm 0.14$ & $159.61 \pm 31.60$ & $3.57 \pm 1.61$ & $4 \pm 1.60$ & $6.06 \pm 2.15$ \\
I. crithmoides & $23.66 \pm 11.07$ & $17.8 \pm 6.84$ & $0.64 \pm 0.40$ & $5.1 \pm 2.78$ & $6.03 \pm 4.83$ & $8.29 \pm 3.90$ \\
S. fruticosa & $6.49 \pm 1.33$ & $0.65 \pm 0.21$ & $0.43 \pm 0.02$ & $51.93 \pm 20.94$ & $5.11 \pm 3.01$ & $49.99 \pm 18.17$ \\
\hline
\end{tabular}


ent at very low levels in the different taxa were excluded from the graphics.

As mentioned before, sucrose is the major carbohydrate in both Juncus species (Tab. 3), but its seasonal variation was statistically significant only in J. acutus ( $\mathrm{F}=5.62$; $\mathrm{df}$ $=4,20 ; \mathrm{P}<0.05)$. The highest sucrose content in J. acutus $\left(148 \mu \mathrm{mol} \mathrm{g}^{-1} \mathrm{DW}\right)$ was measured in the sample collected in summer 2009 , and was significantly different from all other seasons, as revealed by the post-hoc analysis (Fig. 1). Glucose contents also showed significant seasonal differences $(\mathrm{F}=9.07 ; \mathrm{df}=4,20 ; \mathrm{P}<0.05)$; the maximum level of glucose $\left(66 \mu \mathrm{mol} \mathrm{g} \mathrm{g}^{-1} \mathrm{DW}\right)$ was lower than that of sucrose, but was found also in summer 2009; LSD intervals $(\mathrm{P}<0.01)$ showed significant differences with the rest of the samplings. Seasonal variation of fructose contents was qualitatively and quantitatively very similar to that of glucose (Fig. 1). These data support the function of sucrose as an active osmolyte in J. acutus, and suggest its participation in the mechanisms of stress tolerance in this species. Glucose and fructose probably contribute as well to maintaining cellular osmotic balance, albeit to a lesser extent, since they accumulate to lower levels.

The patterns of seasonal changes of the three sugars are similar in J. acutus and J. maritimus, but in the latter species the observed differences were not statistically significant (Fig. 1), which could be due simply to a high variability of carbohydrate contents in individual J. maritimus plants. These two species are closely related taxonomically, but they differ in their tolerance to salt. It has been observed that $J$. maritimus, the most salt tolerant, always contains higher levels of Pro than J. acutus, under the same environmental conditions (unpublished results); therefore, it is also possible that J. maritimus relies mostly on Pro accumulation for osmotic adjustment and the sugars play only a secondary role in salt tolerance mechanisms as functional osmolytes, but this hypothesis remains to be demonstrated.

Sorbitol is the only soluble carbohydrate accumulating at significant levels in Plantago crassifolia, reaching concentrations similar to those described by Ahmad et al. (1979) in P. maritima, another halophyte of the genus. Moreover, seasonal changes in sorbitol contents were clearly correlated with the environmental conditions of the plants (Fig. 2): the highest values (ca. $340 \mu \mathrm{mol} \mathrm{g}^{-1} \mathrm{DW}$ ) were detected in leaves collected in summer 2009, and were significantly different $(\mathrm{F}=38.67$; $\mathrm{df}=4,20 ; \mathrm{P}<0.05)$ from sorbitol levels measured in plants sampled in all other seasons (LSD intervals, $\mathrm{P}<0.001$ ). In fact, changes in sorbitol levels in the plants followed, at least qualitatively, the changes in soil salinity (compare P. crassifolia data from Fig. 2 with EC measurements in Tab. 2). A difference of more than 5 -fold in sorbitol content was observed between the periods of lower (spring 2010) and higher (summer 2009) soil salinity. In previous experiments (Vicente et al., 2004), in which young $P$. crassifolia plants were treated in the greenhouse with increasing salt concentrations, sorbitol contents also increased about 5-fold between $200 \mathrm{mM}$ and $500 \mathrm{mM} \mathrm{NaCl}$, although at lower $\mathrm{NaCl}$ concentrations there was no positive correlation between sorbitol levels in the plants and external salinity.

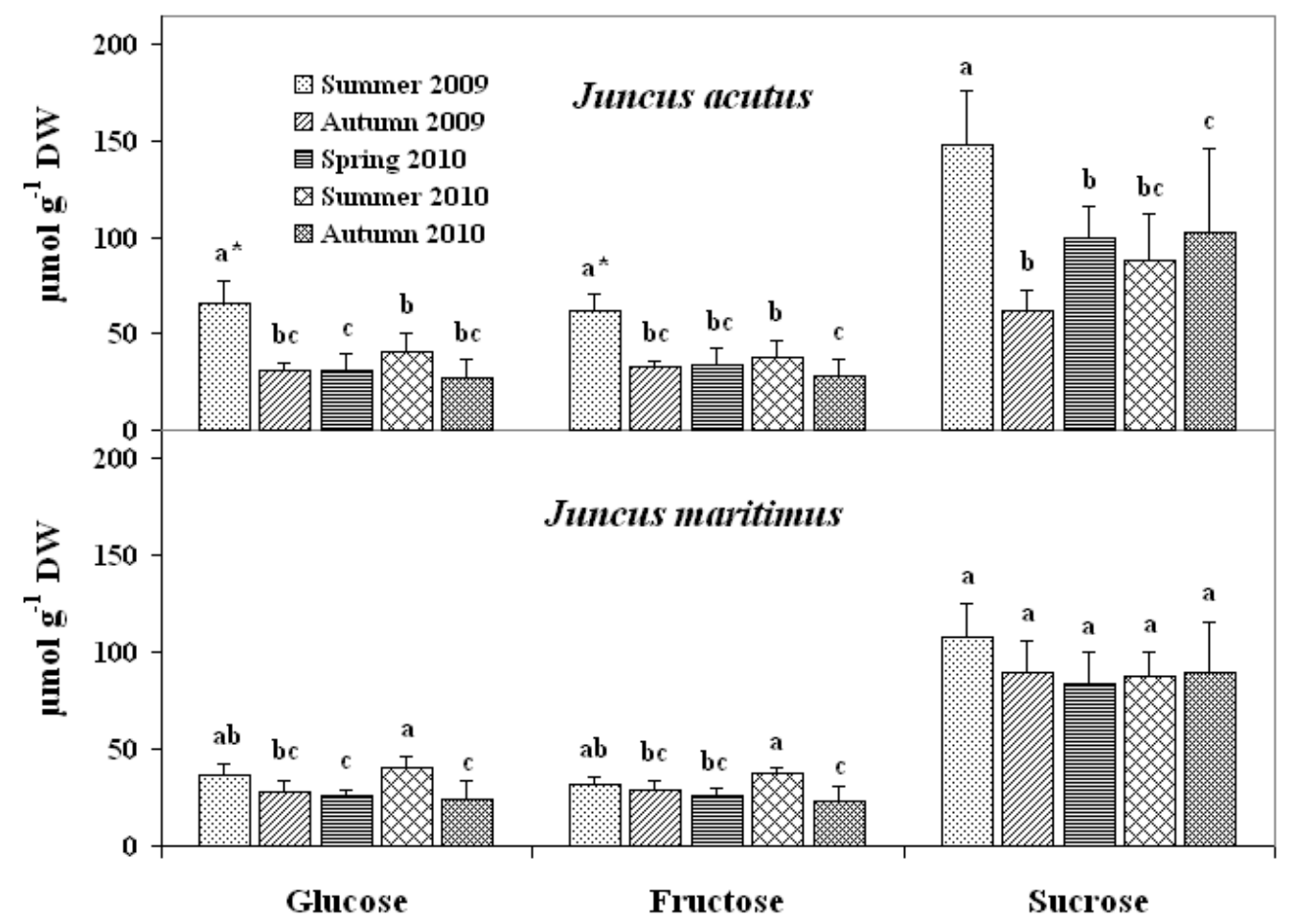

Fig. 1. Seasonal changes of the most abundant carbohydrates in the monocotilyledonous halophytes Juncus acutus and J. maritimus. Carbohydrate contents ( $\mu$ mol g ${ }^{-1} \mathrm{DW}$; mean $\pm S D, n=5$ ) are shown, as indicated; for each of them, values with the same lower-case letter are not significantly different $\left(\mathrm{P}>0.05\right.$; ANOVA followed by LSD). ${ }^{*}$ Significantly different $(\mathrm{P}<0.01)$ 
14

In Inula crithmoides, the most abundant carbohydrates were identified as the polyols myo-inositol and glycerol (Fig. 2). Myo-inositol is a central component of several biochemical pathways in plants, including cell signalling and membrane biogenesis (Nelson et al., 1998), besides its function in osmoregulation under conditions of cellular dehydration. In I. crithmoides, however, myo-inositol contents did not show any clear correlation with the degree of environmental stress, since they were similar in plant material collected in all seasons, except in autumn 2009, in which this polyol was present at significantly lower levels. Therefore, myo-inositol does not seem to be involved in mechanisms of tolerance to salt stress in this taxon. Concerning glycerol, on the contrary, one-way ANOVA revealed statistically significant differences between seasons $(\mathrm{F}=12.55 ; \mathrm{df}=4,17 ; \mathrm{P}<0.05) . \mathrm{LSD}$ intervals showed higher differences between the summer samplings, in 2009 and 2010-that is, when the levels of soil salinity were higher (Tab. 2)-and the rest of seasons studied; these data would indicate that there is some correlation between glycerol levels and environmental stress, suggesting that it could be involved in salt tolerance mechanisms. Glycerol is the main osmolyte in yeast (Hohmann, 2002), and has been identified as an osmoprotective compound in algae (Cui et al., 2010) and cyanobacteria (Salerno et al., 2004) but, its has not been described as a functional compatible osmolyte in angiosperms. In any case, for both, myoinositol and glycerol, even the maximal levels detected in I. crithmoides plants-about $30 \mu \mathrm{mol} \mathrm{g}{ }^{-1} \mathrm{DW}$-are probably too low to have any significant effect on the maintenance of cellular osmotic balance under salt stress conditions. The levels of other osmolytes have been determined in the same individual plants used for the present study, and it was found that I. crithmoides accumulates relatively high concentrations of GB (unpublished data), which is, most likely, the major compound responsible for osmoregulation in this species.
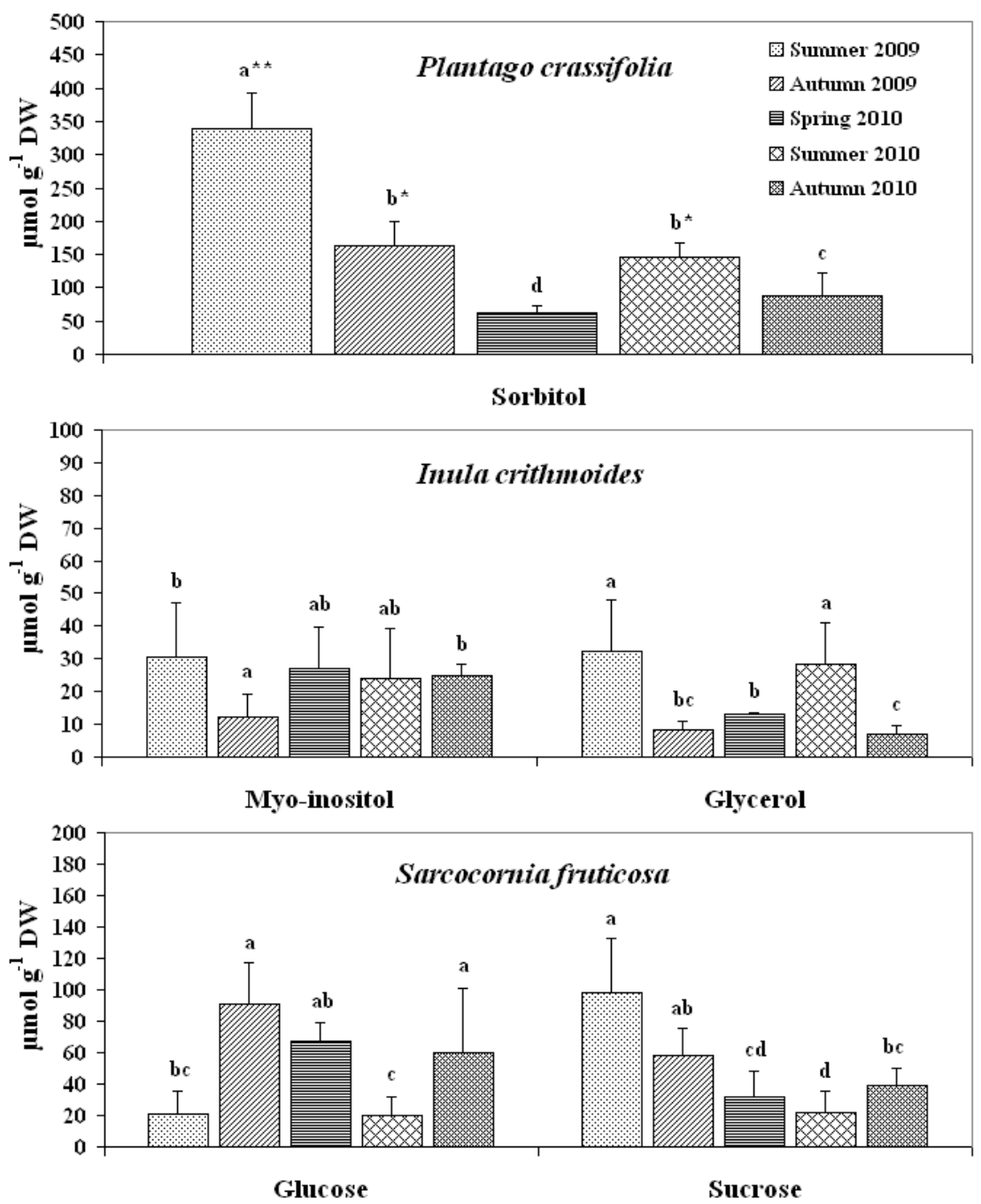

Fig. 2. Seasonal changes of the most abundant carbohydrates in the dicotilyledonous succulent halophytes Plantago crassifolia, Inula crithmoides, and Sarcocornia fruticosa. Carbohydrate contents ( $\mu \mathrm{mol} \mathrm{g}^{-1} \mathrm{DW}$; mean $\pm \mathrm{SD}, \mathrm{n}=5$ ) are shown, as indicated; for each of them, values with the same lower-case letter are not significantly different $\left(\mathrm{P}>0.05\right.$; ANOVA followed by LSD). ${ }^{*}$ Significantly different $(\mathrm{P}<0.01) .{ }^{* *}$ Significantly different $(\mathrm{P}<0.001)$ 

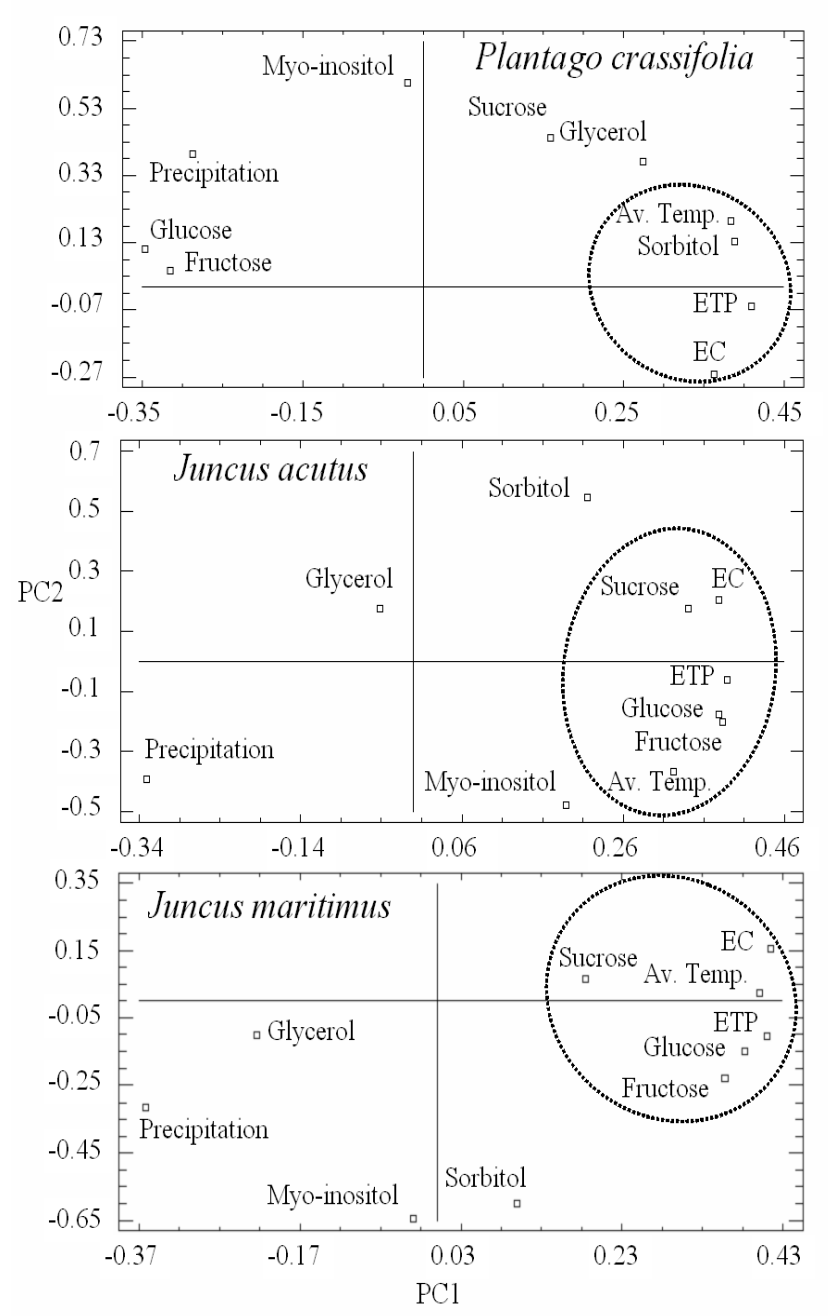

Fig. 3. Site score plot of the studied variables on the two principal components (PC1, PC2) of the halophytes Plantago crassifolia, Juncus acutus, and J. maritimus. Carbohydrates: Fructose, Glucose, Glycerol, Myo-inositol, Sorbitol, and Sucrose. Edaphoclimatic variables: Av. Temp. (average temperature), EC (electrical conductivity), ETP (evapotranspiration), Precipitation

From the five halophytes investigated, Sarcocornia fruticosa is probably the most salt-tolerant. This species is found in coastal salt marshes in SE Spain, growing under a very wide range of interstitial soil salinity; it is able to tolerate very high and continued exposure to salt, and maintains a high growth rate even at $0.5 \mathrm{M} \mathrm{NaCl}$ (Redondo-Gómez et al., 2006). In the present study, glucose and sucrose proved to be the carbohydrates present at higher concentrations in $S$. fruticosa, with average values of ca. $50 \mu \mathrm{mol} \mathrm{g}^{-1} \mathrm{DW}$ (Tab. 3) and maximal contents of 90-100 $\mu \mathrm{mol} \mathrm{g}^{-1} \mathrm{DW}$ (Fig. 2). Significant differences in the levels of these sugars were found among seasons $(F=5.66$ and $10.23 ; \mathrm{df}=4,18$; $\mathrm{P}<0.05)$. Regarding their seasonal variations, there was no clear correlation of glucose contents and soil salinity or meteorological data, whereas maximal sucrose contents were measured in the samples from the very dry summer of 2009 but, as described above for J. acutus and P. crassifolia, they were not maintained in those from summer
2010. As I. crithmoides, S. fruticosa synthesises high levels of GB (data not shown), and apparently does not rely on carbohydrates for osmoregulation. Some related species from the same family, such as Salicornia europaea L. and $S$. prostrata Pall. have been shown to accumulate GB (Tipirdamaz et al. 2006), although the former species seems to use also methylated sulphonium compounds as osmolytes (Briens and Larher, 1982).

\section{Principal Components Analysis (PCA) of carbohydrates}

To confirm mathematically the apparent correlations observed between the seasonal changes in carbohydrate levels and the corresponding soil and climatic characteristics of the experimental area, PCA was applied to the data described above.

In $P$. crassifolia, PCA yields two principal components (PC1, PC2), with eigenvalues $>1$; together they explained $81.37 \%$ of the total variation. The first PC (57.33\%) was positively dominated by sorbitol, evapotranspiration (ETP), average temperature (Av. Temp.), and electrical conductivity (EC) (Fig. 3). Pearson product-moment correlation coefficient between each pair of variables confirmed to be significant $(\mathrm{P}<0.05)$ for the variable-group noted. Sobitol was highly correlated with ETP $(r=0.91)$ and Av. Temp. $(r=0.92)$ and, with somehow lower significance, also with EC $(r=0.75)$. Precipitation was also significantly, but negatively correlated with sorbitol $(r=$ $-0.55)$. Obviously, PC1 is mostly related to soil humiditywhich will decrease in periods of low precipitation and high ETP-and concentration of salts, both essential factors conditioning salt stress in plants. PC2 (24.04\%), on the other hand, was mainly dominated by myo-inositol, sucrose, and glycerol on the positive side, but the low levels of these carbohydrates indicate that they do not play any important role in the compensation of osmotic stress in $P$. crassifolia.

In Juncus acutus and J. maritimus, three PCA components (PC1, PC2, PC3), with eigenvalues > 1, explained 91.55 and $82.21 \%$ of the total variation, respectively. In both cases, PC1 was positively correlated with glucose, fructose, sucrose, ETP, EC, and Av. Temp. In J. acutus, glucose and fructose were correlated, with high statistical significance, positively with EC (both $r=0.81), \operatorname{ETP}(r=$ $0.9,0.92)$, and Av. Temp. $(r=0.83,0.86)$, and negatively with Precipitation $(r=-0.65,-0.64)$; sucrose was positively correlated with EC $(r=0.78)$ and ETP $(r=0.68)$, and negatively with Precipitation $(r=-0.76)$. This behaviour was slightly different in the case of J. maritimus: glucose and fructose also correlated positively with $\mathrm{EC}(r=0.63$, $0.54)$, ETP $(r=0.69,0.64)$, and Av. Temp. $(r=0.71,0.88)$, and negatively with Precipitation $(r=-0.43)$, but less significantly than in J. acutus. Sucrose, on the other hand, was not significantly correlated with any abiotic variable, but its accumulation at high levels in J. maritimus suggested that it is related to osmotic compensation: one-way ANOVA of LOG (sucrose), using EC as factor, was statistically significant $(\mathrm{F}=1.17 ; \mathrm{df}=4,20 ; \mathrm{P}<0.05)$. As in $P$. crassifo- 
16

lia, PC1 was positively correlated with variables related to an increase of soil salinity and, consequently, to the activation of osmoregulatory mechanisms in the plants. In both, J. maritimus and J. acutus, low loadings of PC2 (11.4\% and $21.36 \%$, respectively) and PC3 (12.82\% and $11.07 \%)$, were obtained.

In $I$. crithmoides and $S$. fruticosa, PCA did not reveal any clear interactions between carbohydrates and the environmental parameters studied (data not shown).

\section{Conclusions}

Seasonal variations of carbohydrates contents have been investigated in five selected halophytes, growing in their natural habitat in a littoral salt marsh in SE Spain, with the aim to establish their possible function as 'compatible osmolytes' and their contribution to the mechanisms of salt tolerance in the different plant species. Sorbitol is the only soluble carbohydrate present at significant levels in Plantago crassifolia. Sorbitol contents correlated positively with high temperatures, evapotranspiration and electrical conductivity of the soil, and negatively with precipitation; that is, they varied in parallel with the intensity of salt stress affecting the plants during the course of the year. These data showed that sorbitol is the major functional osmolyte in $P$. crassifolia, as has been demonstrated for all other species of this genus investigated previously. The same correlations with edaphoclimatic parameters were found for sucrose, glucose and fructose in Juncus acutus and J. maritimus. Considering the relative levels reached by these sugars, sucrose appears to be the involved in osmoregulation, with minor contributions of the less abundant glucose and fructose. In Inula crithmoides and Sarcocornia fruticosa, no clear correlation was found between soluble carbohydrates contents and salt stress; in addition, the levels of these compounds are generally too low to have any significant effect on maintaining cellular osmotic balance under stress conditions.

\section{Acknowledgements}

This study was supported by the Spanish Ministry of Science and Innovation (project CGL2008-00438/BOS), with contribution from the European Regional Development Fund.

\section{References}

Ahmad I, Larher F, Stewart GR (1979). Sorbitol, a compatible osmotic solute in Plantago maritima. New Phytol 82:671678.

Álvarez-Rogel J, Jiménez-Cárceles FJ, Roca MJ, Ortíz R (2007). Changes in soil and vegetation in a Mediterranean coastal salt marsh impacted by human activities. Estuar Coast Shelf S 73:510-526.

Andersen R, Sorensen A (2000). Separation and determination of alditols and sugars by high-pH anion-exchange chromatography with pulsed amperometric detection. J
Chromatogr A 897:195-204.

Ashraf M, Harris PJC (2004). Potential biochemical indicators of salinity tolerance in plants. Plant Sci 166:3-16.

Aubert S, Assard N, Boutin JP, Frenot Y, Dorne AJ (1999). Carbon metabolism in the subantartic Kerguelen cabbage Pringlea antiscorbutica R. Br.: environmental controls over carbohydrates and proline contents and relation to phenology. Plant Cell Environ 22:243-254.

Bartels D, Sunkar R (2005). Drought and salt tolerance in plants. Crit Rev Plant Sci 24:23-58.

BeMiller JN (2010). Carbohydrate analysis, 147-177 p. In: Nielsen SS (Ed.). Food analysis, $4^{\text {th }}$ Ed. Springer, New York.

Boscaiu M, Estrelles E, Soriano P, Vicente O (2005). Effects of salt stress on the reproductive biology of the halophyte Plantago crassifolia. Biol Plant 49:141-143.

Boyer JS (1982). Plant productivity and environment. Science 218:443-448.

Briens M, Larher F (1982). Osmoregulation in halophytic higher plants: a comparative study of soluble carbohydrates, polyols, betaines and free proline. Plant Cell Environ 5:287292.

Cataldi TRI, Campa C, De Benedetto GE (2000). Carbohydrate analysis by high-performance anion-exchange chromatography with pulsed amperometric detection: The potential is still growing. Fresen J Anal Chem 368:739-758.

Chapman VJ (1974). Salt marshes and salt deserts of the world, 392 p. $2^{\text {nd }}$ Ed. Cramer J, Lehre, Germany.

Cram WJ (1976). Negative feedback regulation of transport in cells. The maintenance of turgor, volume and nutrient supply, 284-316 p. In: Luttge U, Pitman MG (Eds.). Encyclopaedia of plant physiology. Springer-Verlag, Berlin.

Cui L, Chai Y, Li J, Liu H, Zhang L, Xue L (2010). Identification of a glucose-6-phosphate isomerase involved in adaptation to salt stress of Dunaliella salina. J Appl Phycol 22:563-568.

Flowers TJ, Colmer TD (2008). Salinity tolerance in halophytes. New Phytol 179:945-963.

Flowers TJ, Galal HK, Bromham L (2010). Evolution of halophytes: multiple origins of salt tolerance in land plants. Funct Plant Biol 37:604-612.

Flowers TJ, Hajibagheri MA, Clipson NJW (1986). Halophytes. Q Rev Biol 61:313-335.

Gadallah MAA (1999). Effects of proline and glycinebetaine on Vicia faba responses to salt stress. Biol Plant 42:249-257.

Gajewski M, Katarzyna K, Bajer M (2009). The influence of postharvest storage on quality characteristics of fruit of eggplant cultivars. Not Bot Horti Agrobo 37:200-205.

Gao Z, Sagi M, Lips SH (1998). Carbohydrate metabolism in leaves and assimilate partitioning in fruits of tomato (Lycopersicon esculentum L.) as affected by salinity. Plant Sci 135:149-159.

Glenn EP, Brown JJ, Blumwald E (1999). Salt tolerance and crop potential of halophytes. Crit Rev Plant Sci 18:227-255.

Gorham J, Hughes L, Wyn Jones RG (1980). Chemical composition of salt-marsh plants from Ynys Môn (Anglesey): 
the concept of physiotypes. Plant Cell Environ 3:309-318.

Grigore MN, Boscaiu M, Vicente O (2011). Assessment of the relevance of osmolyte biosynthesis for salt tolerance of halophytes under natural conditions. Eur J Plant Sci Biotech 5:12-19.

Gupta AK, Kaur N (2005). Sugar signalling and gene expression in relation to carbohydrate metabolism under abiotic stresses in plants. J Biosci 30:761-776.

Hare PD, Cress WA, Van Staden J (1998). Dissecting the roles of osmolyte accumulation during stress. Plant Cell Environ 21:535-553.

Hohmann S (2002). Osmotic adaptation in yeast-control of the yeast osmolyte system. Int Rev Cytol 215:149-187.

Hussain TM, Chandrasekhar T, Hazara M, Sultan Z, Saleh BK, Gopal GR (2008). Recent advances in salt stress biology-a review. Biotechnol Mol Biol Rev 3:8-13.

Ishitani M, Majumder AL, Bornhouser A, Michalowski CB, Jensen RG, and Bohnert HJ (1996). Coordinate transcriptional induction of myo-inositol metabolism during environmental stress. Plant J 9:537-548.

Jouve L, Hoffmann L, Hausman JF (2004). Polyamine, carbohydrate, and proline content changes during salt stress exposure of Aspen (Populus tremula L.): involvement of oxidation and osmoregulation metabolism. Plant Biol 6:7480.

Kerepesi I, Galiba G (2000). Osmotic and salt stress-induced alteration in soluble carbohydrate content in wheat seedlings. Crop Sci 40:482-487.

Khan MA, Ungar IA, Showalter AM (2000). Effects on sodium chloride treatments on growth and ion accumulation of the halophyte Haloxylon recurvum. Commun Soil Sci Plant Anal 31:2763-2774.

Königshofer H (1983). Changes in ion composition and hexitol content of different Plantago species under the influence of salt stress. Plant Soil 72:289-296.

Koyro HW (2006). Effect on salinity on growth, photosynthesis, water relations and solute composition of the potential cash crop halophyte Plantago coronopus (L.). Environ Exp Bot 56:136-146.

Koyuncu MA, Dilmaçünal T (2010). Determination of vitamin $\mathrm{C}$ and organic acid changes in strawberry by HPLC during cold storage. Not Bot Horti Agrobo 38:95-98.

Lidón A, Boscaiu M, Collado F, Vicente O (2009). Soil requirements of three salt tolerant, endemic species from South-East Spain. Not Bot Horti Agrobo 37:64-70.

Munns R, Tester M (2008). Mechanisms of salinity tolerance. Annu Rev Plant Biol 59:651-681.

Murakeözy ÉP, Nagy Z, Duhazé C, Bouchereau A, Tuba $\mathrm{Z}$ (2003). Seasonal changes in the levels of compatible osmolytes in three halophytic species of inland saline vegetation in Hungary. J Plant Physiol 160:395-401.

Nelson DE, Rammesmayer G, Bohnert HJ (1998). Regulation of cell-specific inositol metabolism and transport in plant salinity tolerance. Plant Cell 10:753-764.

Nelson DW, Sommers LE (1982). Total carbon, organic carbon and organic matter, 539-579 p. In: Miller AL, Miller DH (Eds.). Methods of soil analysis, ASA, SSSA, Madison, Wisconsin.

Noiraud N, Maurousset L, Lemoine R (2001). Transport of polyols in higher plants. Plant Physiol Bioch 39:717-728.

Owens S (2001). Salt of the Earth. Genetic engineering may help to reclaim agricultural land lost due to salinisation. EMBO Rep 2:877-879.

Parida A, Das AB, Das P (2002). NaCl stress causes changes in photosynthetic pigments, proteins and other metabolic components in the leaves of a true mangrove, Bruguiera parviflora, in hydroponic cultures. J Plant Biol 45:28-36.

Parida KA and Das AB (2005). Salt tolerance and salinity effects on plants: a review. Ecotox Environ Safe 60:324-349.

Parvaiz A, Satyawati S (2008). Salt stress and phyto-biochemical responses of plants-a review. Plant Soil Environ 54:89-99.

Pommerrenig B, Papini-Terzi FS, Sauer N (2007). Differential regulation of sorbitol and sucrose loading into the phloem of Plantago major in response to salt stress. Plant Physiol 144:1029-1038.

Popp M, Smirnoff N (1995). Polyol accumulation and metabolism during water stress, $199-215$ p. In: Smirnoff M (Ed.). Environment and plant metabolism. Flexibility and acclimatation. Bioscientific Publishers Ltd, Oxford.

Redondo-Gómez S, Wharmby C, Castillo JM, Mateos-Naranjo E, Luque CJ, de Cires A, Luque T, Davy AJ, Figueroa ME (2006). Growth and photosynthetic responses to salinity in an extreme halophyte, Sarcocornia fruticosa. Physiol Plant 128:116-124.

Sairam RK, Tyagi A (2004). Physiology and molecular biology of salinity stress tolerance in plants. Curr Sci India 86:407421.

Salerno GL, Porchia AC, Vargas WA, Abdian PL (2004). Fructose-containing oligosaccharides: novel compatible solutes in Anabaena cells exposed to salt stress. Plant Sci 167:1003-1008.

Serrano R (1996). Salt tolerance in plants and microorganisms: toxicity targets and defense responses. Int Rev Cytol 165:152.

Szabados L, Savouré A (2010). Proline: a multifunctional amino acid. Trends Plant Sci 15:89-97.

Tipirdamaz R, Gagneul D, Duhazé C, Aïnouche A, Monnier C, Özkum D, Larher F (2006). Clustering of halophytes from an inland salt marsh in Turkey according to their ability to accumulate sodium and nitrogenous osmolytes. Environ Exp Bot 57:139-153.

Vicente O, Boscaiu M, Naranjo MA, Estrelles E, Bellés JM, Soriano P (2004). Responses to salt stress in the halophyte Plantago crassifolia (Plantaginaceae). J Arid Environ 58:463481.

Vinocur B, Altman A (2005). Recent advances in engineering plant tolerance to abiotic stress: Achievements and limitations. Curr Opin Biotech 16:123-132.

Zhu J-K (2001). Plant salt tolerance. Trends Plant Sci 6:66-71. 